\title{
Anticuerpos Contra Virus Rubeola y Herpes en Mujeres que Atienden Recién Nacidos Hospitalizados
}

\author{
Dra. Tamara Montero B.; Dra. Pamela Barraza C.; Dra. Mónica Suárez G.; \\ Dr. Luis F. Ayendaño C. 1 . \\ Antibodies Against Herpes Simplex and Rubella Vinuses
in Women at Work With Newborns in a Hospital Setting
}

\begin{abstract}
Herpes simplex and rubella viruses cause severe infections in the newborn; and they are now potentially preventable. The presence of antibodics against both viruses was investigated in a fertile female population that works in two nearby teaching hospitals at Northern Santiago. Three groups of women were included: 89 medical student; 35 members of the professional staff (medical doctors \& nurses) and 32 members of the auxiliary personnel of a local Hospital's Neonatal care unit. Antirubella virus antibodies were detected in $99,4 \%$ of the total study populations, thus confuming previous resuits that show a high degree of positive findings of serum antibodies against rubella in the chilean adult female population. Among the auxiliary personnel the proportion of positive antibody detection against herpes simplex virus was significantly higher (94\%), than in the other two groups (74\%). This results correlates well with a clinical history of recurrent symptomatic herpes simplex episodes in $48,5 \%$ of this subjects.
\end{abstract}

(Key words: Herpes Simplex and Rubella virus antibodies. Serum. Women health students and professionals).

La rubeola y el herpes simplex son infecciones virales de importancia en la mujer en edad fértit, ya que pueden ser transmitidas de madre a hijo y producir en éste infecciones fetales o neonatales de consecuencias serias ${ }^{1,3,5}$.

La rubeola postnatal es una enfermedad infecciosa benigna que se contrae generalmente en el período preescolar o escolar y se presenta con mucha frecuencia en forma subclínica ${ }^{2}$. El interés por esta enfermedad aumentó notablemente desde 1941, cuando se postuló asociación entre rubeola ocurrida en el embarazo y malformaciones congénitas del recién nacido ${ }^{1}$. Actualmente se sabe que la infección de la madre por el virus de la rubeola en el primer trimestre del embarazo puede comprometer la placenta y producir infección crónica del producto o malformaciones congénitas severas en el recién nacido o ambas. Las

1. Sección Virología, Departamento de Microbiología y Parasitología, Div. Ciencias Médicas Norte, Facultad de Medicina, Universidad de Chile.

* Financiado por el Depto. de Investigación y Bibliotecas, Dirección General Académica, Universidad de Chile. Proyecto de Investigación M 1871-8413. alteraciones más frecuentemente observadas son las malformaciones cardiovasculares, cataratas y bajo peso de nacimiento, que pueden ser acompa. ñados por signos de infección crónica, como hepatomegalia, esplenomegalia, pürpura, ictericia y meningoencefalitis $1,3,4,5$. Desde 1969 se cuenta con una vacuna a virus atenuado de buena calidad contra la rubeola, cuyo uso no ha sido considerado prioritario en Chile ${ }^{23}$, razón por la cual tiene gran importancia conocer las manifestaciones de inmunidad de la población femenina de alto riesgo con el fin de determinar si este grupo debería ser sometido a inmunización antes de embarazarse.

$\mathrm{La}$ infección de los genitales por virus herpes simplex constituye otra enfermedad viral que puede ser fuente de infección para el feto o el recièn nacido. El herpes genital es una afección venérea que ha experimentado un notable incremento en los últimos años ${ }^{18}$. Una característica muy particular del virus herpes simplex es su capacidad de persistir en estado latente en los ganglios sensitivos de la persona infectada, después de la primoinfección, pudiendo periódicamente reactivarse y provocar enfermedades recu. rrentes ${ }^{9}$. Esta infección puede ser transmitida 
por la madre al hijo fundamentalmente en el parto durante el paso del nifo por el canal genital infectado con virus herpes simplex. También el feto podría adquirir la infección por vía genital ascendente, en casos de rotura prematura de membranas de más de 24 horas de evolución. Un tercer mecanismo de transmisión, aunque menos frecuente, es la via transplacentaria. Existe tam. bién la posibilidad de infección del recién nacido después del parto a través de su contacto con lesiones herpéticas no genitales, de las mucosas o la piel de la madre o el personal que lo atiende 6 . 15. A veces ocurren reactivaciones asintomáticas del virus herpes simplex en las que, sin embargo se elimina el agente infeccioso por vía genital, lo que representa una fuente de infección inaparente $^{17}$. Se pueden aplicar actualmente medidas preventivas eficaces contra la infección herpética de los recién nacidos, para lo cual es necesario identificar $y$ realizar un adecuado manejo clínico de las embarazadas de alto riesgo 6,12 .

En este estudio se investigaron las concentraciones de anticuerpos circulantes como indice del nivel de inmunidad a los virus herpes y rubeola en una población femenina que, por razones de trabajo, está expuesta con mayor frecuencia a infecciones virales.

\section{MATERIAL Y METODO}

Se estudiaron tres diferentes grupos de mujeres relacionadas con la atención de salud, en la zona Norte de Santiago: 89 estudiantes universitarias del Hospital Clínico J.J. Aguirre (medicina y enfermería) con edad promedio de 22 años, 32 auxiliares de enfermería de la Unidad de Recièn Nacidos del Hospital Roberto del Rio, cuyo promedio de edad era 29 años y 35 profesionales (médicos y enfermeras) con 30 años de edad promedio.

Todas las mujeres incorporadas al estudio fueron encuestadas personalmente por uno de los investigadores sobre antecedentes de manifestaciones clínicas de rubeola y herpes oral, genital o glúteo, épisodios herpéticos recurrentes y la frecuencia anual de estos últimos. En cada caso se tomó una muestra de sangre para estudio serológico de rubeola y herpes simplex. Ambos procedimientos fueron realizados entre los meses de Marzo y Noviembre de 1983.

Para los estudios serológicos el suero se mantuvo congelado a $-20^{\circ} \mathrm{C}$ hasta su análisis, el que fue hecho después de terminar la recolección de todas las muestras. Los anticuerpos contra el virus de la rubeola se investigaron mediante la técnica de Inhibición de la Hemaglutinactón (IHA), descrita por Stewart ${ }^{14}$, tratando los sueros contra inhibidores inespecíficos con Heparina y Cloruro de manganeso ${ }^{16}$. La determinación de anticuerpos para virus herpes simplex se realizó mediante la técnica de Hemaglutinación Indirecta (HAI), siguiendo el método descrito por Bernstein y Stewart ${ }^{1} \mathbf{l}$.

\section{RESULTADOS}

Más de $90 \%$ de las mujeres estudiadas (alumnas, profesionales y auxiliares) tеnian edades menores de 35 artos, por lo tanto se trataba de una población en un rango etario de mảxima fertilidad (Fig. 1).

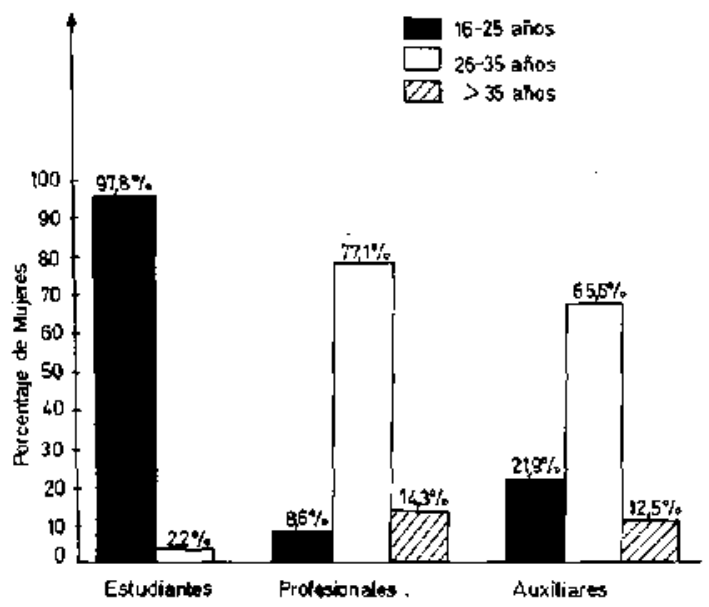

Figura 1. Distribución por cdades de 156 mujeres: 86 estudiantes universitarias, 35 profesionales y 32 auxiliares de enfermería del Area Norte de Salud de Santiago, sometidas a estudios serológicos para detectar anticuerpos contra virus herpes simplex y rubeola.

Una alta proporción de los sujetos de los tres grupos tenia antecedentes de herpes oral, destacando especialmente el grupo de auxiliares de enfermería con $53,1 \%$ de respuestas positivas. El antecedente de rubeola clínica ocurrió en 19 de las 156 mujeres estudiadas ( $12,2 \%$ del total).

En los estudios serológicos en $74 \%$ de las estudiantes $y$ profesionales se detectaron anticuerpos contra los virus del herpes simplex, observándose proporciones significativamente mayores $(p<0,05)$ en el grupo de auxiliares de enfermería (93,8\%). En $99,4 \%$ de las mujeres estudiadas se encontraron anticuerpos contra el virus de la rubeola, sin diferencias significativas entre los diferentes grupos estudiados (Tabla 1).

En las mujeres con antecedentes clínicos de infección herpética se encontraban anticuerpos 
contra el virus en un porcentaje superior al grupo sin antecedentes (Tabla 2). Este hecho fue esta. disticamente significativo en los grupos de estudiantes $y$ de profesionales $(p<0,01)$. La presen. cia de anticuerpos anti-rubeola se observó independientemente de los antecedentes clínicos de la enfermedad.

\section{DISCUSION}

El censo serológico de rubeola en las tres poblaciones de mujeres del àrea de salud, mostró que casi todas tenian anticuerpos contra la rubeola, en porcentaje superior al detectado en otros estudios hechos en el país ${ }^{7}, 10$. En estudios de mujeres primigestas entre 15 y 20 años de edad $^{10}$ y en universitariäs chilenas ${ }^{7}$ se encontraron anticuerpos anti-rubeola en proporciones semejantes de los sujetos $(90,8 \%)$. El mayor por- centaje de mujeres seropositivas detectado entre las que trabajan en hospitales podría ser explicado por las mayores probabilidades de contacto con el yirus de la rubeola en establecimientos asistenciales. Otra razón podría ser mayor sensibilidad de la técnica de IHA que usa Heparina-Mn para remover inhibidores inespecificos de los sueros con respecto a la que utiliza Kaolin ${ }^{16}$. Esta posibilidad es discutible ya que existen estudios que no revelan diferencias significativas en los resultados. de ambas técnicas, aunque existen preferencias por parte de los investigadores hacia la técnica con Heparina $-\mathbf{M n}^{1}{ }^{9}$.

Los antecedentes clínicos positivos de rubeola tienen escaso valor en la pesquisa de inmunidad contra el virus; en nuestro estudio observamos que se obtenian en un porcentaje muy bajo de las tres poblaciones encuestadas, en contraste con la gran proporción de las mujeres en que se detecta-

Tabla 1.

Detección de anticuerpos contra virus Herpes Simplex y Rubeola en mujeres (estudiantes, profesionales y auxiliares) ocupadas en actividades de salud

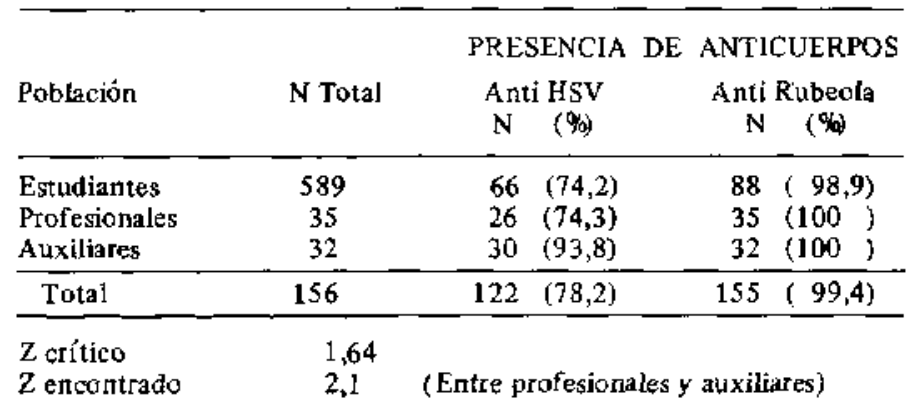

Tabia 2.

Relación entre antecedentes clínicos de enfermedad por Herpes Simples y detección de anticuerpos contra el virus en mujeres que estudian y trabajan en actividades de salud.

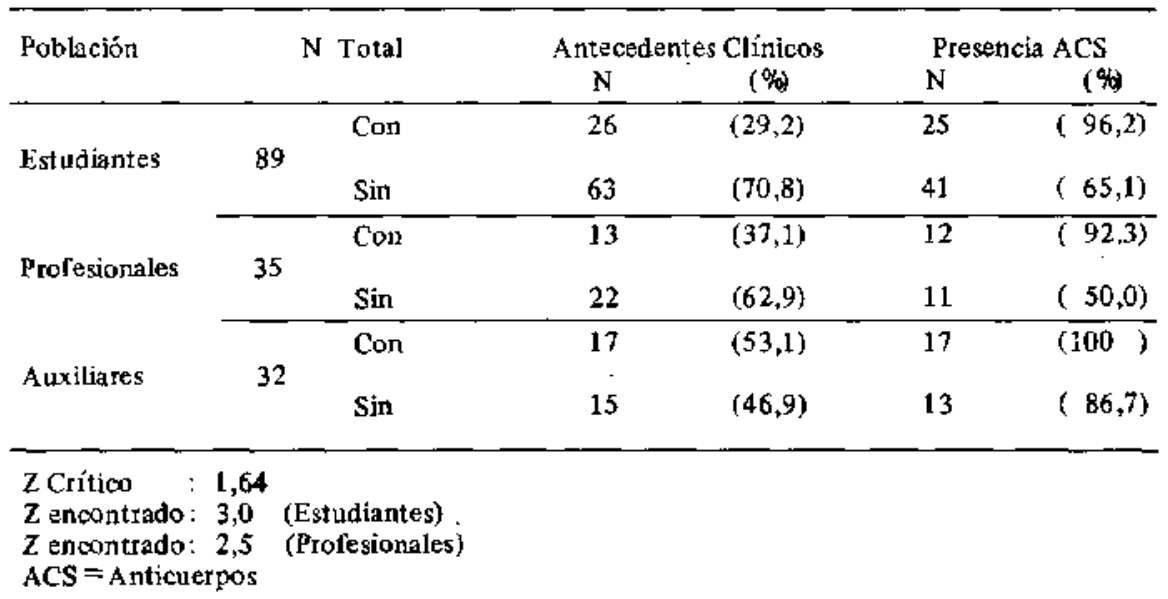


ron anticuerpos. La situación anterior confirmaría que, si bien la mayor parte de las infecciones por virus rubeola son subclínicas, la inexactitud del antecedente de rubeola podria tener relación con las conocidas difjcultades que tiene el diag. nóstico diferencial de los exantermas morbilifor. mes durante la infancia. El simple antecedente de anamnesis de rubeola clínica no puede ser considerado como información válida para identificar el grupo poblacional que debería recibir vacunación. La política de vacunación chilena difiere de la de EE.UU,, donde desde 1969 se aplica un programa de vacunación que incluye toda la población de niños (mujeres y varones) entre ly 12 años de edad y de mujeres mayores de 12 años no embarazadas y susceptibles al virus rubeola ${ }^{8}$. Con este programa se ha logrado dismi. nuir la incidencia de rubeola en aproximadamente 5 veces desde que se comenzó a usar la vacuna 13 . En Inglaterra el programa de vacuna. ción se concentra en niñas entre 11 a 14 años de edad y la vacunación selectiva en mujeres no embarazadas susceptibles ${ }^{8}$. Los resultados obtenidos en esta $y$ otras investigaciones nacionales 7 . 10 , apoyan la conducta de no vacunar obligatoriamente a las mujeres chilenas, pues existe una adecuada tasa de inmunidad en la población fernenina.

La mayor proporción de auxiliares de enfermeria en quienes se detectaron anticuerpos contra virus herpes simplex respecto de los otros grupos analizados, podría ser explicada asumiendo que existe un nivel socio-económico más bajo entre las auxiliares, pues esta relación ha sido demostrada en varios trabajos 20,21 .

El antecedente de herpes labial apareció en una muestra con una frecuencia muy superior a la que ocurre en la población generat ${ }^{22}$, lo que podría explicarse por la mayor familiaridad de nuestros sujetos con este tipo de afecciones, to que facilita y hace más fidedigna la información. En contraste, un estudio realizado recientemente en otro grupo de la población chilena femenina de edad y condición socioeconómica semejantes, cuya actividad no pertenecia al área de salud, se obtuvo este antecedente sólo en el $20 \%$ de la población ${ }^{17}$. Lo anterior sugiere que en la infección herpética son factores importantes la edad, la situación socio-económica y también la ocupación del individuo. El hecho que un grupo de auxiliares pertenecientes a unidades de recién nacidos tenga alta frecuencia de herpes labial, es importante, y subraya la necesidad de enfatizar el cuidado que se debe tener en los centros de atención de recién nacidos respecto al personal que en ellos trabaja y su rol como posibles fuentes de contagio. Es de fundamental importancia la adecuada información sobre los riesgos y las precauciones que deben ser aplicadas respecto al virus herpes en reciën nacidos, especialmente la necesidad de excluir de las unidades de atención neonatal a toda persona con lesiones herpéticas activas.

\section{RESUMEN}

Los virus herpes simplex y rubeola son capaces de producir infecciones connatales graves, para las cuales existe actualmente prevención. Se investigó la presencia de anticuerpos contra ambos en una población femenina que trabaja en et sector salud frente a estos virus.

Se estudiaron 3 grupos de mujeres, 89 eran estudiantes de medicina o enfermeria, 35 profesionales de las mismas disciplinas y 32 auxiliares de enfermería en una Unidad de Recién Nacidos. El $99.4 \%$ de las mujeres investigadas teniz anticuerpos antirubeola, confirmándose que existe un alto grado de inmunidad contra el virus en la población femenina adulta chilena.

Con respecto al virus herpes, se encontraron tasas de seropositividad significativamente mayo. res en el personal auxiliar de recién nacidos (94\%) que en las estudiantes y profesionales (74\%). Se encontró también con mayor frecuencia antecedentes de infecciones herpéticas en dicho grupo $(48,5 \%)$, situación que es especialmente significativa dado que se trata de personal que trabaja directamente con recién nacidos.

\section{REFERENCIAS}

1. Hortsmann, D.: Viral Infections. In Medjcal Complications during Pregnancy. Burrow, G, Ferris, T. I1: 414, 1975 .

2. Krugnom, S., Ward, $R .:$ In Infectious Diseases of Childten. Eds. The C.V. Mosby Co., St. Louis. U.S.A. 4a. Ed. 1968, pág. 279.

3. Greenberg, M., Peliteri, O., Barton, J.: Frequency of Defects in Infants whose Mothers had Rubelk during Pregnancy. J.A.M.A. 165: 675, 1957.

4. Krugman, $S$. IVard, $R$.: The Rubella Problem. J. Pediatr. 44: 489, I954.

5. Naeye, $R$, Blanc, $W$ : Pathogenesis of congenital rubella. J.A.M.A. 194: 1277, 1965.

6. Suárez, M., Dubinowsky, S.: Virus Herpes: Rol en la Infección Neonatal. Rev. Chil. Pediatr. 55. 431, 1984.

7. Vergara, M.I. y colab,: Evaluación estado inmunológico anti rubeola en las alumnas de in Universidad de Chile. Respuesta serológica a la vacuna. Comunicación libre. VIII Congreso Chileno de Microbiología. Luiversidad Austral de Chile, Valdivia, 1984.

8. Krugman, S.: Present status of measles and rubella immunization in the United States: A Medical Progress Report. J. Pediatr. 90: 1, 1977. 
9. Suárez, M.: Virus Herpes Simplex, Nucvos Aspectos de las Infecciones Genitales Herpéticas. Simposio Avances en Patología Viral. Series Clínicas Souiciad Médies de Santiago. Edit. Roselot E., Velaseo is., Santiago, Editoria] Univer sitaria. 2: púg. 99, 1983.

10. Potiomielitis, Sarampion y Rubeola-Censo Serob́. gico. Boletin de Vigilantin Epidemiolígica. Ministe. rio de Salud, República de Chile 11: 3, 1984.

11. Bernstein, M., Stcwart, J.: Method lor typing antisera to herpes hominis by indirect hemaglutination inhibition. Appl. Microbin). 21: 680, 1971.

12. De lo Moza, L., Peterson, E.: Genital Infections. Symposium on Medical Virology. Med. Clin. North Am. 67: 1059, 1983.

13. Contreras, $G_{.}$: Control de las enfermedades vilales mediante vacunas. En Adetantos en Microbiología y Enfermedades Infecciosas, Coto, C., Esparza, J, de Tortes, R.; 1: 157, 1982.

14. Stewart, $G$. et $d$ : Rubella virus hemaglutimation inhibition test. N. Enel. J. Med. 276: 554, 1967.

15. Whitley, R., Nohmios, A. ef al.: The Natural History of Hespes Simplex Virus Infection of Mother and Newborn. Pediatrics 66: 499, 1980.

16. Herinamn. K.: Rubella virus. In Dagnostic Procedures for Viral, Rickettsial and Chlanydial Infections. I,ennette E., Schmidt, N. 5th Ed. American Public
Health Association Inc. Washington U.S.A. 25; pág. $739,1979$.

17. Súnê, M., Rojas, P., Herrera, S, Pacheco, I., Tapia, L.: Asytnptomatic genital herpes infection in a olitean Temale population. Bull. Pan. Am. Health Organ. (anviado a publicación).

18. Center jor Disease Control. "Genital herpes Infection [Tited States, 1966-1979", MMWR 31: 137, 1982.

19. Suggs, M, Brés, $P$. ef al.: Evaluation of candidate international reference methods for the rubela heMigiutination inhibition test: report of a collaborative study. Bull. Pan Am. Health Organ. 17: 281, 1983.

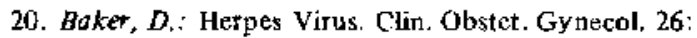
$165,1983$.

21. Nahmias, A.J, Roizman, B.: Infection with Herpes Simplex Yiruses 1 and 2. N. T.ngl. J. Med. 289: 667, 1973.

22. Bader, $C$. ef al.: The natural history of recurrent facial-oral infection with herpes simplex virus. J. Infect, Dis, 138: 897, 1978 .

23. Anónimo: Calendario de Vacunaciones. Boletín de Vigitancia Epideniológica del Ministerio de Salud. República de Chile. 11: 23, 1984. 